Article

\title{
Microstructure and Material Properties of Ti-15mass\%Nb Alloy after Gas Nitriding and Quenching Process
}

\author{
Yoshikazu Mantani ${ }^{1, *}$, Kentaro Shimada ${ }^{2}$ and Naoki Eguchi ${ }^{2}$ \\ 1 Department of Materials Science and Engineering, National Institute of Technology (KOSEN), \\ Suzuka College, Suzuka 510-0294, Japan \\ 2 Advanced Engineering Course of Science and Technology for Innovation, National Institute of \\ Technology (KOSEN), Suzuka College, Suzuka 510-0294, Japan; h30a11@ed.cc.suzuka-ct.ac.jp (K.S.); \\ r02a03@ed.cc.suzuka-ct.ac.jp (N.E.) \\ * Correspondence: mantani@mse.suzuka-ct.ac.jp; Tel./Fax: +81-59-368-1843
}

Received: 30 November 2020; Accepted: 17 December 2020; Published: 18 December 2020

\begin{abstract}
The $\alpha^{\prime}$ martensite of Ti- 15 mass $\% \mathrm{Nb}$ alloy exhibits high internal friction with high damping properties. However, its structure is smoother than the $\alpha+\beta$ structure. Therefore, a hardened surface layer is required for abrasion resistance. This study fabricated a martensite structure inside the nitriding layer by quenching, after gas nitriding at 1023 and $1223 \mathrm{~K}$. Vickers hardness test, X-ray diffraction, scanning electron microscopy (SEM), and SEM-energy dispersive X-ray (SEM-EDX) measurements from the surface to the inside were made after the heat treatment process. In addition, the Young's modulus and internal friction were calculated from the damping analysis. The $\alpha-\mathrm{TiN}_{0.3}$ and $\beta$ phase region was formed at approximately $80 \mu \mathrm{m}$ from the surface at 1023 and $1223 \mathrm{~K}$, and it was hardened. The internal friction of the gas nitriding and quenching specimens at 1023 and $1223 \mathrm{~K}$ was relatively high, though it did not reach that of the as-quenched specimen owing to the influence of the surface structure. From these results, it is considered that these material property values of the alloy can be controlled using the nitriding and quenching processes.
\end{abstract}

Keywords: titanium alloy; martensite; nitriding; hardness; internal friction $\mathrm{Q}^{-1}$; Young's modulus $E$; microstructure; phase constitution

\section{Introduction}

Although titanium and its alloys have been used as structural materials, various studies have employed its functional properties, such as low Young's modulus $E$ [1-3], shape memory effect [4-6], and super elasticity [6-9]. In addition to the functional properties, it was established that the $\alpha^{\prime}$ martensite structure of the Ti- 15 mass $\% \mathrm{Nb}$ alloy exhibits high internal friction $\mathrm{Q}^{-1}$ with high damping properties [10-12]. However, the $\alpha^{\prime}$ martensite structure is smoother than that of the $\alpha+\beta$ structure [10]. Therefore, a hardened surface layer is required for abrasion resistance. The nitriding is often performed as a typical surface treatment method for hardening a titanium alloy. There are many reports on the plasma nitriding [13-18] and gas nitriding [19-27] of titanium and its alloys. However, there are few reports on the nitriding of $\mathrm{Ti}-\mathrm{Nb}$ alloy systems or the martensite structure of titanium alloys.

Plasma nitriding occurs at a wide range of temperatures from approximately 773 to $1373 \mathrm{~K}$, whereas gas nitriding occurs at only high temperatures ranging from approximately 973 to $1273 \mathrm{~K}$. Therefore, to obtain high hardness and high damping properties, a nitriding process at a relatively low temperature while maintaining the martensite structure of the titanium alloy and forming a martensite structure after nitriding at a high temperature can be considered. In the former, we attempted the plasma nitriding of Ti- 15 mass $\% \mathrm{Nb}$ alloy at a relatively low temperature range of approximately 
$773 \mathrm{~K}$, but only the outermost surface could be hardened. Therefore, this study fabricated a martensite structure inside the nitriding layer by quenching after gas nitriding at 1023 and $1223 \mathrm{~K}$.

\section{Materials and Methods}

Ti-15mass $\% \mathrm{Nb}$ alloy was used in this study. It was cut to achieve the following dimensions: $15 \times$ $10 \times 1 \mathrm{~mm}$ for the Vickers hardness test (HM-220D; Motutoyo, Kawasaki, Japan), scanning electron microscopy (SEM) (S-4300; HITACHI, Tokyo, Japan), and X-ray diffraction (XRD) measurement (SmartLab; Rigaku, Tokyo, Japan), and $70 \times 7 \times 1 \mathrm{~mm}$ for damping analysis (DS3000; Ono Sokki, Yokohama, Japan). The specimen was placed on a quartz boat and then poured into a quartz tube in an electric furnace, and the evacuation process and nitrogen gas substitution were repeated three times. The nitrogen gas used had a purity of $99.999 \%$, and it was set to a pressure of $0.15 \mathrm{MPa}$. After heating at 1023 or $1223 \mathrm{~K}$ and holding for $3.6 \mathrm{ks}$ in a nitrogen atmosphere, the quartz boat was soaked in ice water for quenching. This heat treatment is called the gas nitriding and quenching process (GNQP). The Vickers hardness test was performed at intervals of $20 \mu \mathrm{m}$ for the cross-sectional depth direction with a test force of $0.01 \mathrm{kgf}$ and a holding time of $15 \mathrm{~s}$. Damping analysis was performed via the free resonance method. The attenuation waveform of the vibration amplitude was read, and the frequency response function was obtained. The $E$ was calculated from the resonance frequency, and the $\mathrm{Q}^{-1}$ was calculated from the Hilbert calculation. Mirror-polished cross-sectional specimens were used for SEM observation and SEM-energy dispersive X-ray (EDX) measurement. The constituents of the layer from the surface to a depth of $150 \mu \mathrm{m}$ were investigated via XRD analysis of $\mathrm{CuK} \alpha(40 \mathrm{kV}, 30 \mathrm{~mA})$. The GNQP specimens were ground to 10,50 , and $150 \mu \mathrm{m}$ from the surface.

\section{Results}

Figure 1 shows the cross-sectional SEM microstructure after GNQP. A brighter layer was formed on the surface for the microstructure at $1023 \mathrm{~K}$ (a). In addition, a dense acicular structure of $30 \mu \mathrm{m}$ and sparse long acicular structure of $50 \mu \mathrm{m}$ were observed. At $1223 \mathrm{~K}(\mathrm{~b})$, the first layer of $10 \mu \mathrm{m}$, a dense massive structure layer of $16 \mu \mathrm{m}$ and a sparse massive structure of $54 \mu \mathrm{m}$ were formed. At the corner area of the specimen (c), a wide area lamellar microstructure was formed in addition to the first layer of $10 \mu \mathrm{m}$.
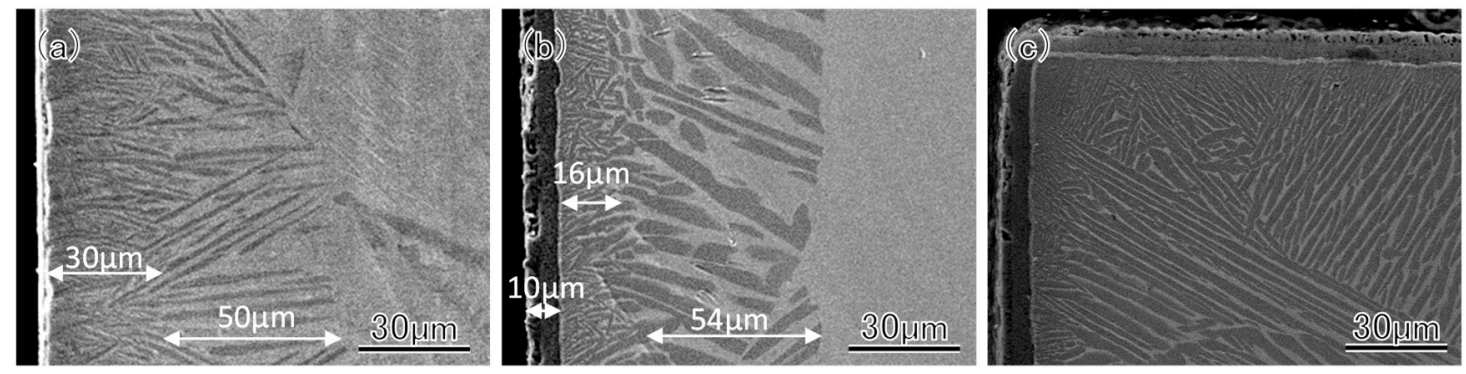

Figure 1. Cross-sectional SEM microstructure after the gas nitriding and quenching process (GNQP). (a) Edge area at $1023 \mathrm{~K}$. (b) Edge area at $1223 \mathrm{~K}$. (c) Corner area at $1223 \mathrm{~K}$.

Figure 2 shows the micro Vickers hardness distribution from the surface after GNQP. At $1023 \mathrm{~K}$, the hardness of the surface layer was $540 \mathrm{HV}$, and it was $327 \mathrm{HV}$ at a depth of $100 \mu \mathrm{m}$. The hardness of the $\alpha^{\prime}$ martensite in the alloy was approximately $240 \mathrm{HV}$ [10], which is equivalent to that observed at a position deeper than $250 \mu \mathrm{m}$. Conversely, the hardness of the surface layer was $720 \mathrm{HV}$ at $1223 \mathrm{~K}$, which was $450 \mathrm{HV}$ at a depth of $100 \mu \mathrm{m}$. At deeper positions, almost the same hardness value was maintained, and it did not drop to a similar hardness to that of the $\alpha^{\prime}$ martensite. 


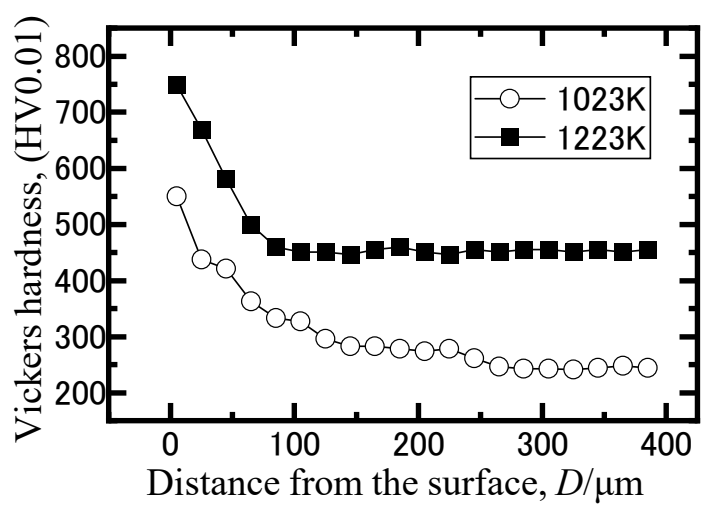

Figure 2. Micro Vickers hardness distribution from the surface after GNQP.

Figure 3 shows the change in the XRD profile from the surface. For comparison, the XRD profiles of the as-annealed (AN) and the as-quenched (AQ) specimens at 1023 and $1223 \mathrm{~K}$ are shown in the figure [11,12]. From Figure 3, it can be observed that the AN has a mixed phase structure of the $\alpha$ phase and the $\beta$ phase. However, in the $A Q$, the supersaturated $\alpha^{\prime}$ martensite exhibits a diffraction peak shifted to a lower angle than the $\alpha$ phase; thus, it can be observed that the $\alpha^{\prime}$ martensite expanded. Comparing the calculated lattice constants of the $\alpha^{\prime}$ martensite with the annealed $\alpha$ phase from the XRD profiles, expansion of the a-axis is approximately $0.8 \%$ and that of the c-axis is approximately $0.2 \%$. At the surface XRD profile at $1023 \mathrm{~K}$ (a), the diffraction peaks of $\mathrm{TiO}_{2}, \mathrm{TiN}_{1} \mathrm{Ti}_{2} \mathrm{~N}$, and $\alpha-\mathrm{TiN}_{0.3}$ were detected. In addition to the $\alpha$-TiN 0.3 peak, $\beta$ phase diffraction peaks were detected in the XRD profile after $10 \mu \mathrm{m}$ grinding. After $50 \mu \mathrm{m}$ grinding, it was considered that the structure contained the $\alpha^{\prime}$ martensite. After $150 \mu \mathrm{m}$ grinding, for some percentage of the structure to be changed into the $\alpha^{\prime \prime}$ martensite, the peaks were split. For the surface at $1223 \mathrm{~K}(\mathrm{~b})$, the diffraction peaks of $\mathrm{TiO}_{2}$ were very strong. However, very weak peaks of $\mathrm{TiN}, \mathrm{Ti}_{2} \mathrm{~N}$, and $\alpha-\mathrm{TiN}_{0.3}$ were also detected. Similar to that at $1023 \mathrm{~K}, \alpha-\mathrm{TiN}_{0.3}$ and $\beta$ phase were detected at $10 \mu \mathrm{m}$, and the $\alpha^{\prime}$ martensite was detected at $50 \mu \mathrm{m}$. Because the diffraction peak of the $\alpha^{\prime}$ martensite is very broad, residual strain is generated. Moreover, a part of the structure is formed as an $\alpha^{\prime \prime}$ martensite from the separation state of the peak. Even after $150 \mu \mathrm{m}$ grinding, the diffraction peak was still broadened, and a large residual strain was introduced during the formation of the martensite.

Figure 4 shows the cross-sectional SEM-EDX analysis results after GNQP at $1023 \mathrm{~K}$. In the SEM image (a), the position where the point analysis was performed and the mapping range surrounded by the light blue frame area are shown. Nitrogen and oxygen were detected at the outermost surface (1) of the point analysis result (b), and a decrease in Ti content was observed. This is attributed to the formation of nitrides and oxides. Almost no nitrogen and oxygen were detected in regions (2) to (5), marked on (a). A decreased content of $\mathrm{Nb}$ was observed in the dark region (3), whereas it increased in the bright region (4). In region (5), the default amount of $\mathrm{Nb}$ is shown. In the element mapping result (c), a region of increased/decreased $\mathrm{Ti}$ and $\mathrm{Nb}$ contents detected via point analysis was detected. Although it is difficult to evaluate the distribution of $\mathrm{N}$, an increase in $\mathrm{O}$ was observed in the outermost surface region.

Figure 5 shows the cross-sectional SEM-EDX analysis results after GNQP at $1223 \mathrm{~K}$. The position of the point analysis and the mapping range are indicated in the SEM image (a). The amount of oxygen detected at the outermost surface (1) of the point analysis result is high (b), indicating that it is an oxide film layer. It can be observed that nitrogen is detected and diffused in region (2). The amount of $\mathrm{Nb}$ decreased in the dark region (3), whereas it increased in the bright region (4). In the element mapping result (c), a region of increased/decreased $\mathrm{Ti}$ and $\mathrm{Nb}$ contents detected via point analysis could be confirmed. In addition, the distribution of nitrogen corresponds to the region with a high amount of Ti. The distribution of oxygen was confirmed in the outermost surface region, and it was established that a $\mathrm{TiO}_{2}$ layer was formed. 
(a)

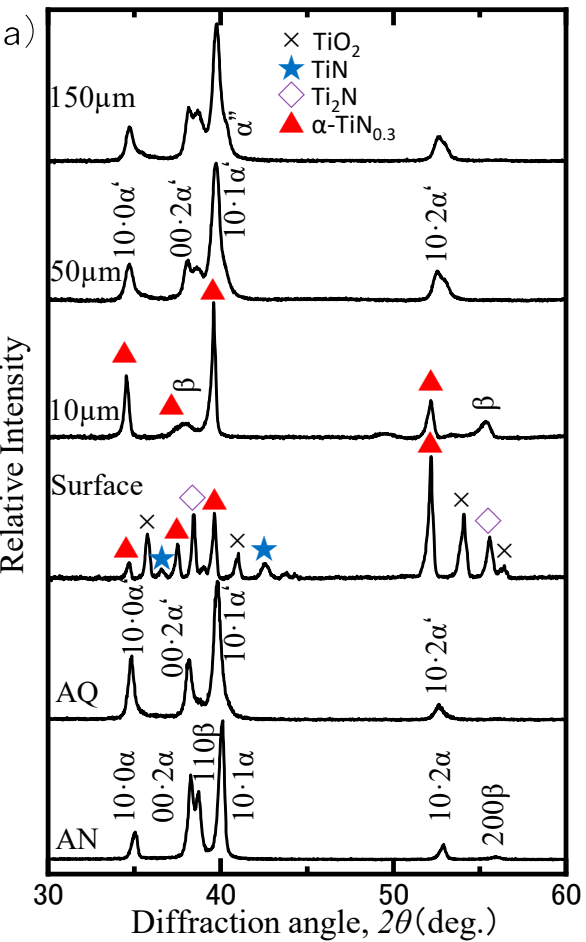

(b)

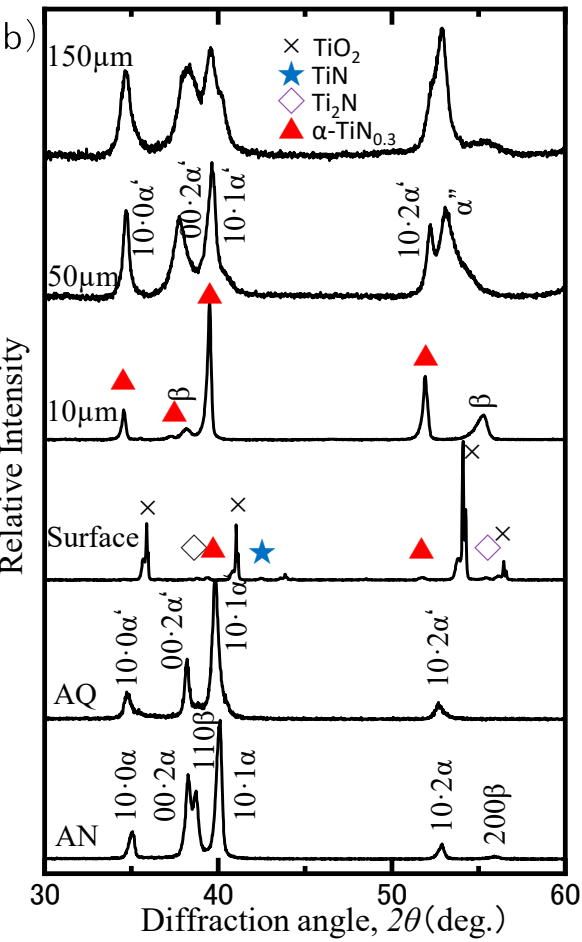

Figure 3. Change in the XRD profile from the surface to the depth direction. (a) $1023 \mathrm{~K}$. (b) $1223 \mathrm{~K}$.
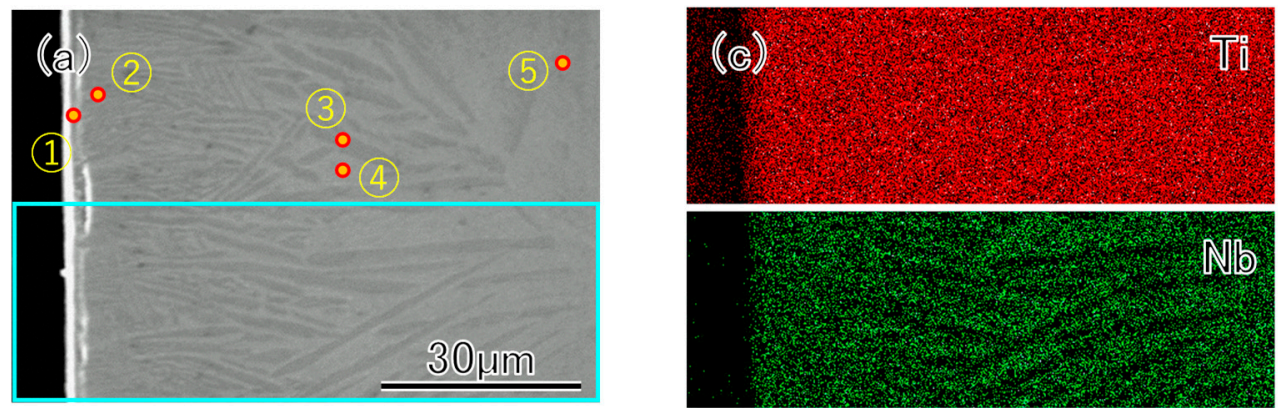

(b)
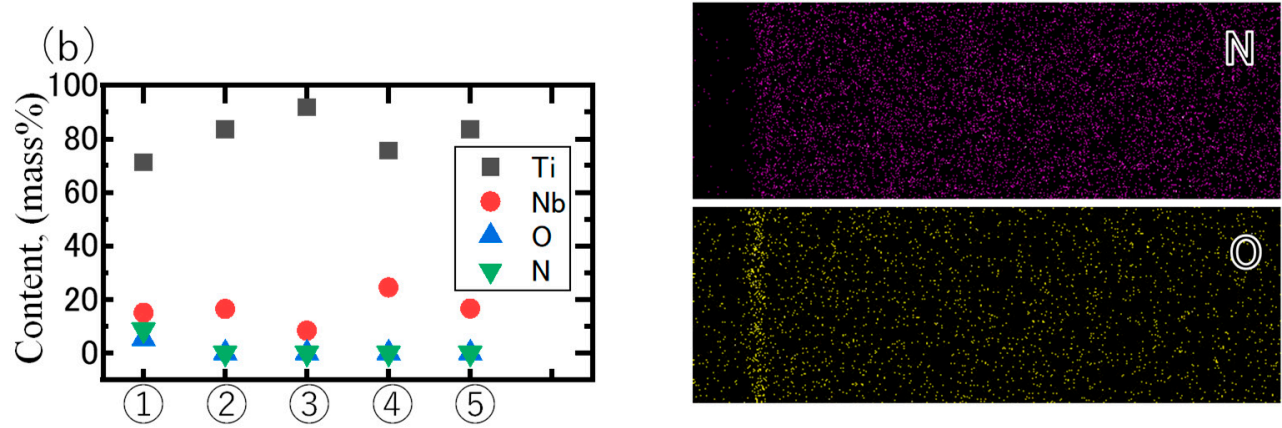

Figure 4. Cross-sectional SEM-EDX analysis results after GNQP at $1023 \mathrm{~K}$. (a)SEM microstructure. (b) The result of point analysis at the position indicated by the number of (a). (c) The element mapping results of $\mathrm{Ti}, \mathrm{Nb}, \mathrm{N}$ and $\mathrm{O}$. 

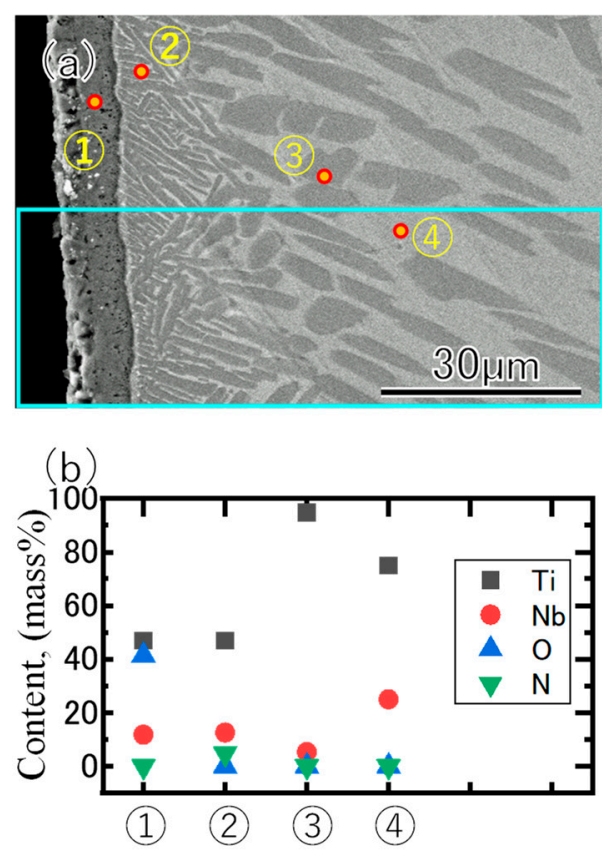
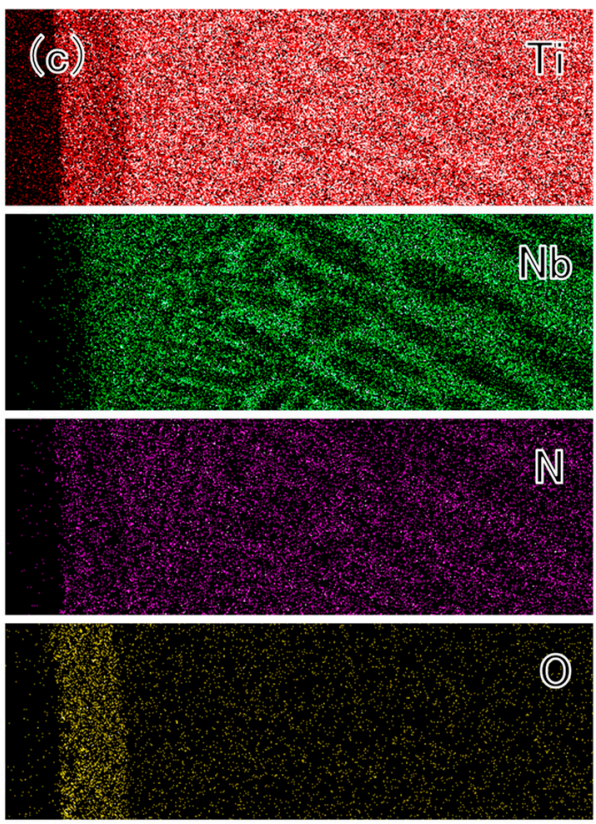

Figure 5. Cross-sectional SEM-EDX analysis results after GNQP at $1223 \mathrm{~K}$. (a)SEM microstructure. (b) The result of point analysis at the position indicated by the number of (a). (c) The element mapping results of $\mathrm{Ti}, \mathrm{Nb}, \mathrm{N}$ and $\mathrm{O}$.

Figure 6 shows the $E(\mathrm{a})$ and the $\mathrm{Q}^{-1}(\mathrm{~b})$ after each heat treatment. The $E$ of the Ti- $15 \mathrm{Nb}$ alloy $\mathrm{AN}$ specimen with $\alpha+\beta$ structure is $92.5 \mathrm{GPa}$, whereas that of the AQ specimen with the $\alpha^{\prime}$ martensite structure is $58.3 \mathrm{GPa}$ [10-12]. That of the specimen after GNQP at $1023 \mathrm{~K}$ was $87.9 \mathrm{GPa}$, whereas that of the specimen after GNQP at $1223 \mathrm{~K}$ was $79.6 \mathrm{GPa}$, indicating a high value close to that of the AN specimen, although the $\alpha^{\prime}$ martensite structure was formed. Conversely, the $Q^{-1}\left(\times 10^{-3}\right)$ of the AQ specimen increased from 0.3 to 6.2 , showing high damping properties. The $\mathrm{Q}^{-1}$ of the specimen after GNQP at $1023 \mathrm{~K}$ was 3.6, whereas that of the specimen after GNQP at $1223 \mathrm{~K}$ was 4.4, indicating relatively high values, although not as high as that of the AQ specimen. Notably, these changes are consistent with the influence of the formed layer and the state of the $\alpha^{\prime}$ martensite structure.
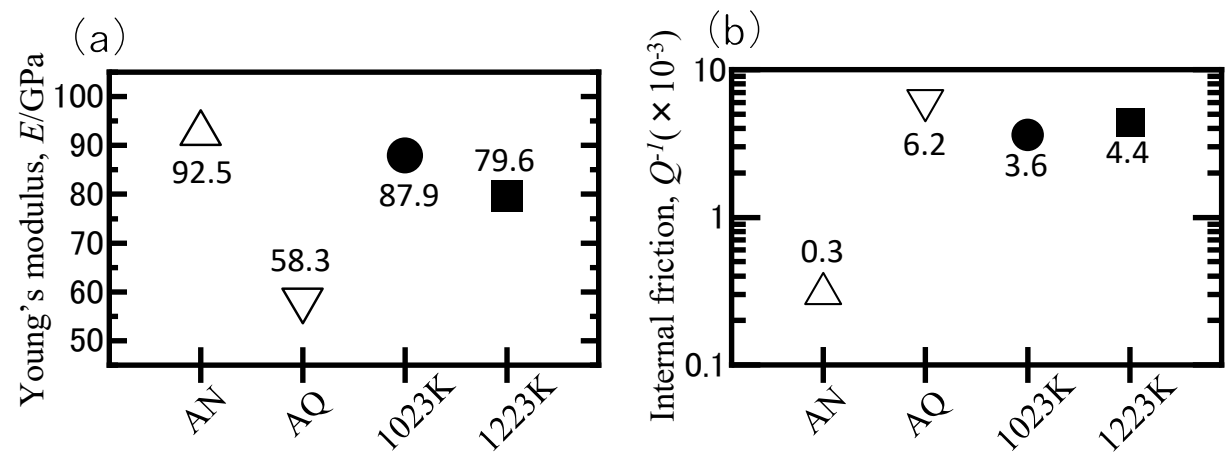

Figure 6. Change in material properties after each heat treatment. (a) Young's modulus E. (b) Internal friction $Q^{-1}$.

\section{Discussion}

The microstructural state is discussed based on the results of the Vickers hardness test, X-ray diffraction, and SEM-EDX analysis. The oxide film layer formed on the outermost surface was formed during water quenching. During gas nitriding, nitrogen diffuses from the surface to a depth of approximately $80 \mu \mathrm{m}$, and nitrides are formed in the portion close to the surface layer. In addition, because nitrogen diffuses in $\alpha-\mathrm{Ti}, \alpha-\mathrm{TiN}_{0.3}$ with a low $\mathrm{Nb}$ content is formed. Moreover, the portion 
with a high $\mathrm{Nb}$ content becomes a $\beta$ phase, and it remains even after quenching. In particular, GNQP at $1223 \mathrm{~K}$ is significantly affected by the structural change of the surface layer, and the residual strain remains inside the specimen during quenching and shows high hardness. Conversely, the base value of hardness is high in gas nitriding at temperatures above $1223 \mathrm{~K}$, and a similar phenomenon occurs [23].

The specimen after GNQP at $1023 \mathrm{~K}$ exhibited an $E$ value closer to that of the AN specimen than that of the AQ specimen. According to the XRD results shown in Figure 3, the $\alpha^{\prime}$ martensite structure is formed at $80 \mu \mathrm{m}$ from the surface layer. Notably, the actual value is slightly lower, but according to this measurement method, it is possible that it was significantly influenced by the acicular structure of the surface layer. Further factors need to be explored. The $\mathrm{Q}^{-1}$ is relatively high, which corresponds to the value of the $\alpha^{\prime}$ martensite structure inside [10-12]. Conversely, the specimen after GNQP at $1223 \mathrm{~K}$ exhibited a relatively high $E$. This is attributed to the increase in hardness and the effect of the surface structure. Further, when the $\mathrm{Q}^{-1}$ of the alloy was increased, the hardness reduced and the $E$ decreased. However, after the GNQP treatment, the hardness increased, the $E$ increased, and the $\mathrm{Q}^{-1}$ was relatively high, although it was not as high as that of the AQ specimen. From these results, it is considered that the material property values of the alloy can be controlled by the GNQP heat treatment.

\section{Conclusions}

In this study, the changes in the microstructure and material properties of the Ti- $15 \mathrm{mass} \% \mathrm{Nb}$ alloy after GNQP at 1023 or $1223 \mathrm{~K}$ were investigated. The following conclusions were obtained:

(1) As a result of changing the hardness in the depth direction after GNQP, the region of $\alpha-\mathrm{TiN}_{0.3}$ and $\beta$ phase was formed at approximately $80 \mu \mathrm{m}$ at 1023 and $1223 \mathrm{~K}$, and this region was hardened. It was established that the hardness of the $\alpha^{\prime}$ martensite was observed in the region deeper than $250 \mu \mathrm{m}$ at $1023 \mathrm{~K}$, whereas the inside was also very hard at $1223 \mathrm{~K}$. From the XRD result at $1223 \mathrm{~K}$, it was established that although the martensite structure was formed in the internal region, it was extremely strained.

(2) It was established that the $\mathrm{Q}^{-1}$ of the specimens after GNQP was relatively high, though both 1023 and $1223 \mathrm{~K}$ did not reach the AQ specimen due to the influence of the surface structure. In addition, the $E$ showed a high value close to that of the AN specimen. From these results, it is considered that the material property values of the alloy can be controlled by the GNQP heat treatment.

Author Contributions: Conceptualization, Methodology, Validation, Writing: Y.M.; Investigation: K.S. and N.E. All authors have read and agreed to the published version of the manuscript.

Funding: This research received no external funding.

Conflicts of Interest: The authors declare no conflict of interest.

\section{References}

1. Ozaki, T.; Matsumoto, H.; Watanabe, S.; Hanada, S. Beta Ti alloys with low young's modulus. Mater. Trans. 2004, 45, 2776-2779. [CrossRef]

2. Matsumoto, H.; Watanabe, S.; Hanada, S. $\alpha^{\prime}$ martensite Ti-V-Sn alloys with low Young's modulus and high strength. Mater. Sci. Eng. A 2007, 448, 39-48. [CrossRef]

3. Bönish, M.; Calin, M.; Humbeeck, J.V.; Skrotzki, W.; Eckert, J. Factors influencing the elastic moduli, reversible strains and hysteresis loops in martensitic Ti-Nb alloys. Mater. Sci. Eng. C 2015, 48, 511-520. [CrossRef]

4. Kim, H.Y.; Hashimoto, S.; Kim, J.I.; Hosoda, H.; Miyazaki, S. Mechanical Properties and Shape Memory Behavior of Ti-Nb Alloys. Mater. Trans. 2004, 45, 2443-2448. [CrossRef]

5. Kim, J.I.; Kim, H.Y.; Hosoda, H.; Miyazaki, S. Shape Memory Behavior of Ti-22Nb-(0.5-2.0)O(at\%) Biomedical Alloys. Mater. Trans. 2005, 46, 852-857. [CrossRef]

6. Kim, H.Y.; Ikehara, Y.; Kim, J.I.; Hosoda, H.; Miyazaki, S. Martensitic transformation, shape memory effect and superelasticity of Ti-Nb binary alloys. Acta Mater. 2006, 54, 2419-2429. [CrossRef] 
7. Inamura, T.; Fukui, Y.; Hosoda, H.; Wakashima, K.; Miyazaki, S. Relationship between texture and macroscopic transdormation strain in severely colled-rolled Ti-Nb-Al superelastic alloy. Mater. Trans. 2004, 45, 1083-1089.

8. Niinomi, M.; Akahori, T.; Nakai, M. In situ X-ray analysis of mechanism of nonlinear super elastic behavior of Ti-Nb-Ta-Zr system beta-type titanium alloy for biomedical applications. Mater. Sci. Eng. C 2008, 28, 406-413. [CrossRef]

9. Kuramoto, S.; Nishino, K.; Saitou, S. Multifunctional titanium alloy. J. JILM 2005, 55, 618-623. [CrossRef]

10. Mantani, Y.; Tsumura, T.; Nakata, K. Effect of $\alpha^{\prime}$ martensite structure of Ti- $15 \mathrm{Nb}$ alloy on material properties and its surface hardening treatment by plasma nitriding. J. Jpn. Soc. Heat Treat. 2012, 52, 263-268.

11. Mantani, Y.; Kudou, K. Effect of plastic deformation on material properties in martensite structures of Ti-Nb alloys. J. Alloys Comp. 2013, 577S, S448-S452. [CrossRef]

12. Mantani, Y.; Takemoto, Y. Change in crystal structure and material properties with deformation of quenched martensite in Ti-Nb alloys. J. Jpn. Inst. Met. Mater. 2015, 79, 461-467. [CrossRef]

13. Rolinski, E. Mechanism of high-temperature plasma nitriding of titanium. Mater. Sci. Eng. 1988, 100, $193-199$. [CrossRef]

14. Rolinski, E. Surface properties of plasma-nitrided titanium alloys. Mater. Sci. Eng. 1989, A108, 37-44. [CrossRef]

15. Bacci, T.; Pradelli, G.; Tesi, B.; Gianoglio, C.; Badini, C. Surface engineering and chemical characterization in ion-nitrided titanium and titanium alloys. J. Mater. Sci. 1990, 25, 4309-4314. [CrossRef]

16. Sato, T.; Akashi, K. Surface modification of Ti-6Al-4V alloy by plasma nitriding. J. JILM 1992, 42, 650-656. [CrossRef]

17. Da Silva, S.L.R.; Kerber, L.O.; Amaral, L.; Da Santos, C.A. X-ray diffraction measurements of plasma-nitrided Ti-6Al-4V. Surf. Coat. Technol. 1999, 116-119, 342-346. [CrossRef]

18. Kapczinski, M.P.; Kinast, E.J.; Da Dos Santos, C.A. New-surface composition and tribological behavior of plasma nitride titanium. J. Phys. D Appl. Phys. 2003, 36, 1858-1863. [CrossRef]

19. Zhecheva, A.; Sha, W.; Malinov, S.; Long, A. Enhancing the microstructure and properties of titanium alloys through nitriding and other surface engineering methods. Surf. Coat. Technol. 2005, 200, 2192-2207. [CrossRef]

20. Ge, L.; Tian, N.; Lu, Z.; You, C. Influence of surface nanocrystallization on the gas nitriding of Ti-6Al-4V alloy. Appl. Surf. Sci. 2013, 286, 412-416. [CrossRef]

21. Miyagi, M.; Sato, Y.; Mizuno, T.; Sawada, S. ESCA study on nitriding of titanium. J. Jpn. Inst. Metals 1979, 43, 939-947. [CrossRef]

22. Yan, X.; Kato, M.; Nakasa, K.; Morita, K. Evaluation of fracture strength and interfacial strength of titanium-nitride layers formed by gas nitriding of titanium. J. Soc. Mat. Sci. Jpn. 2001, 50, 764-771. [CrossRef]

23. Nakai, M.; Niinomi, M.; Akahori, T.; Ohtsu, N.; Ogawa, M.; Nishimura, H.; Toda, H.; Fukui, H.; Ogawa, M. Surface hardening of biomedical Ti-29Nb-13Ta-4.6Zr and Ti-6Al-4V ELI by gas nitriding. Mater. Sci. Eng. A 2008, 486, 193-201. [CrossRef]

24. Haibin Li, H.; Cui, Z.; Li, Z.; Zhu, S.; Yang, X. Effect of gas nitriding treatment on cavitation behavior of commercially pure Ti and Ti-6Al-4V alloy. Surf. Coat. Technol. 2013, 221, $29-36$.

25. Li, H.; Cui, Z.; Li, Z.; Zhu, S.; Yang, X. Surface modification by gas nitriding for improving cavitation erosion resistance of CP-Ti. Appl. Surf. Sci. 2014, 298, 164-170. [CrossRef]

26. Liu, J.; Suslov, S.; Vellore, A.; Ren, Z.; Amanov, A.; Pyun, Y.S.; Martini, A.; Dong, Y.; Ye, C. Surface nonocystallization by ultrasonic nano-crystal surface modification and its effect on gas nitriding of Ti6Al4V alloy. Mater. Sci. Eng. A 2018, 736, 335-343. [CrossRef]

27. Yang, C.; Liu, J. Intermittent vacuum gas nitriding of TB8 titanium alloy. Vacuum 2019, 163, 52-58. [CrossRef]

Publisher's Note: MDPI stays neutral with regard to jurisdictional claims in published maps and institutional affiliations.

(C) 2020 by the authors. Licensee MDPI, Basel, Switzerland. This article is an open access article distributed under the terms and conditions of the Creative Commons Attribution (CC BY) license (http://creativecommons.org/licenses/by/4.0/). 